\title{
Dev Jani
}

\section{Segmenting Inbound Tourists Using Destination Image: Evidence from Tanzania}

\section{Abstract}

The purpose of this study was to segment inbound tourists to Tanzania using destination image. A selfadministered structured questionnaire was conveniently distributed to inbound tourist to Tanzania in two major international airports in Tanzania. The questionnaire captured destination image using a five point Likert type scale while the demographics, sources of travel information, and travel behavior were captured using dichotomy or multiple choice questions. A total of 625 dully filled questionnaires were used for data analysis. A factor-cluster analysis was used in analyzing the data, with factor analysis serving in reducing the items into few dimensions that were subsequently subjected to stepwise cluster analysis. A hierarchical cluster analysis was used to explore the possible numbers of clusters followed by hierarchical cluster analysis (k-means) that confirmed the appropriate number of clusters. A three cluster solution was obtained with follow up one way ANOVA, t-tests, and Chi-square indicating statistical significance differences between the clusters basing on travel motives and travel behavior. The findings offer practical implications to destination managers on the use of destination image in marketing destinations to different tourist segments. This study explored the possible tourist segments basing on destination image of less researched African context.

Keywords: destination image, segmentation, competitiveness, Tanzania

\section{Introduction}

The overall perception of a place held by an individual and the market at large or what is commonly referred to as destination image is one of the main factors influencing tourist behavior including destination choice (Baloglu \& McCleary, 1999; Beerli \& Martin, 2004a; Tasci \& Gartner, 2007). Such an importance of destination image implies that strategic destination marketers need to appraise the images held by their potential visitors and undertake appropriate marketing strategies to make their destination image more attractive. One of the key marketing strategies is market segmentation that involves dividing the whole heterogeneous market into small homogeneous markets with similar characteristics where the marketers can select the relevant segments and market their products to those segments (Kotler \& Armstrong, 2014).

Segmenting the tourism market has been a common research theme for decades (Dolnicar et al., 2013; Hsu \& Kang, 2007; Prayag et al., 2015) with the common variables used including motivation, tourist sociodemographics, tourist behavior, psychographic, and combination of these factors (Dolnicar, 2014; Tkaczynski $\&$ Rundle-Thiele, 2011). Although destination image is one of the main factors influencing tourists' destination choice and their behavior, there is research paucity in the use of the concept in segmenting the tourism market (Kim et al., 2000; Leisen, 2001; Prayag, 2010). Many of the empirical destination image studies are causal studies considering antecedents and consequences of destination image (Beerli \& Martin, 2004a; Beerli \& Martin, 2004b; Wang \& Hsu, 2010). The dominance of causal studies in destination image is surprising, given the fact that segmentation of tourism market using destination image is a precondition for the successful marketing management of the antecedents of a positive destination image and their consequences (Pike, 2004). The few available studies that used destination image as a segmentation variable have not used the

Dev Jani, PhD, Corresponding author, Associate professor, Marketing Department, University of Dar es Salaam Business School, Dar es Salaam, Tanzania; ORCID ID: https://orcid.org/0000-0002-3760-6714; e-mail: yogi_dev@hotmail.com

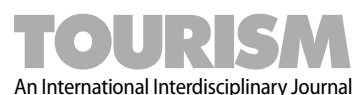


commonly agreed components of destination image that include cognitive and affective destination images (Baloglu \& McCleary, 1999; Beerli \& Martin, 2004a) but rather they seem to have used only the cognitive component (Kim et al., 2000; Leisen, 2001; Prayag, 2010; Prayag et al., 2015). Contextually, no destination image segmentation study has been undertaken in nature based destination (Liu, 2014), particularly in the sub-Saharan African countries (Matiza \& Oni, 2014), which are considered to be an emerging destination for tourists from the more developed countries. The few are available studies in the African context are either conceptual (Matiza \& Oni, 2014) or comparative (Jani \& Nguni, 2016) but not explicitly grouping the inbound tourists. The appraisal and grouping of tourists basing on their images of Africa as a destination is the first step towards strategizing marketing communication that will serve in changing the poor image of the region (Avrahan \& Ketter, 2016). In extending and complementing previous studies on destination image, this study aimed at segmenting inbound tourists to Tanzania using both the cognitive and affective destination image components.

\section{Literature review}

\subsection{Tourism market segmentation}

Market segmentation is the process of dividing a heterogeneous market into smaller markets that consist of individuals sharing similar characteristics (Kotler \& Armstrong, 2014). Upon segmenting the market, marketers can target one of the few selected markets and design, promote, and provide products to the market(s) more profitably and competitively (Kotler \& Armstrong, 2014). The common tourism segmentation variables include geographic characteristics, tourist socio-demographic characteristics, travel behavior, and psychographics (Dolnicar, 2014). The use of psychographic and behavioral factors over the socio-demographic variables in segmenting the tourism market is preferred as the latter variables have been criticized basing on their lower ability in offering an understanding of the market (Fernandez-Hernandez et al., 2016). The psychographic factors that can be used to segment the tourism market include travel motivations and destination image, while the behavior factors include trip characteristics and expenditure (Dolnicar, 2014). As destination image is more related to travel information acquired by the tourist offering a communication or promotion avenue for destination marketers, this study considers destination image to be more strategic, and considers behavioral aspects of tourists as a segmentation variable. Moreover, as travel behavior, including the activities in the destination, is a consequence of destination image among other variables (Pesonen \& Tuohino, 2015); the use of destination image in segmenting the tourism market is more encompassing. Squarely, destination image offers advantage over other possible segmentation variables as it is the genesis of tourism demand (Obenour et al., 2006).

\subsection{Tourist destination image}

Tourists' behaviors depend on their perceived destination images (Baloglu \& McCleary, 1999; Beerli \& Martin, 2004a) and interest on destination image by both researchers and practitioners. Destination image can simply be understood to reflect the set of beliefs, ideas, impressions, and feelings of the people of a place (Crompton, 1979) that influence their behavior towards the place in question. This definition captures both the cognitive and affective destination images which researchers agree to be the main components (Baloglu \& McCleary, 1999; Wang \& Hsu, 2010). The cognitive image reflects the beliefs, ideas, and impressions one has about a place while the affective component reflects the feeling or emotional elements regarding the place (Wang $\&$ Hsu, 2010). These two components of destination image are responsible for the overall image formation of a place that will eventually lead into a behavior of the person, in the current context, tourist behavior.

Despite the plethora of destination image studies, many have focused on elucidating the antecedents of destination image and image formation (Baloglu \& McCleary, 1999; Boo \& Busser, 2005; Martin \& Bosque,

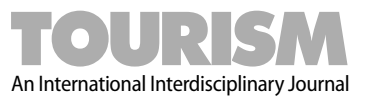


2008) or the consequences of destination image (Chiu et al., 2016; Prayag \& Ryan, 2012; Tavitiyaman \& $\mathrm{Qu}, 2013$; Wang \& Hsu, 2010; Zhang et al., 2014; Tang, 2014). From these many studies, it is evident that destination image studies are more focusing on causality rather than on understanding the market and the possible segments basing on destination images. Such a tilt toward causality research in destination image has also been observed by Tasci et al. (2007) who indicate causal studies in destination image not to provide much practical information that can assist managers, including marketers in profiling the market. From a marketing point of view, once the profitable market segments have been identified, then marketers can undertake marketing strategies directed to the identified segments. In tourism context with reference to destination image, such strategies can relate to the management of the antecedents of destination image as well as managing the consequences of destination image. Thus studies on the profiling of tourists basing on destination images are important.

The main limitation of the available studies on tourist segmentation basing on destination image is the use of one image component, usually the cognitive part (Dryglas \& Salamaga, 2017; Leisen, 2001; Obenour et al., 2006; Prayag, 2010) with very few considering the affective destination image component (Martin \& Rodriguez del Bosque, 2008). None of the existing studies seem to have used both image components in segmenting the tourism market, thus preventing a comprehensive knowledge on destination image.

\subsection{Destination image and travel motives}

Destination image and travel motives have been indicated to be intricately intertwined (Martin \& Rodriguez del Bosque, 2008). In fact, others have used the two concepts or their measures interchangeably (Prayag, 2010) with the same operational definitions. The common conceptualization of travel motives is that of Crompton (1979) that categorizes travel motives into push and pull. The push motives or factors pertain to the intrinsic and psychological desires to travel while the pull factors reflect the extrinsic destination attributes that serve in attracting a person to select a destination (Crompton, 1979). As the push factors are psychological and intrinsic in nature, they can logically relate to the affective destination images (Crompton, 1979). On the other hand, the pull factors are extrinsic, emanating from the destination, and they reflect the cognitive destination image (Prayag, 2010). Despite the two concepts being too intricately intertwined, they have been used separately and distinctively for what appears to be for conceptual and managerial easiness. Basing on the clear relationship between the concepts, this study assumes that, if destination image can be used to logically segment the tourism market, then the travel motives will be reflected on the differences in the distinct travel markets segments.

\subsection{Destination image and information sources}

Traditionally, destination image and the use of different sources of travel information have been intricately linked, with the former being an antecedent of the latter (Beerli \& Martin, 2004b; Gover \& Go, 2003; Martin-Santana et al., 2017; Tasci \& Gartner, 2007). As destination image is the impression held by a tourist (Crompton, 1979) that results from the information from myriad sources (Gartner, 1993), then destination marketing organizations need to know how the different tourists use the different sources of travel information and thereafter manage the content and accessibility of the different sources of travel information. Despite the managerial importance in understanding the usage of different sources of travel information by different tourist segments, an exploration of different tourist segments basing on their held destination image with respect to the usage of different sources of travel information is scanty (Obenour et al., 2006). Obenour et al. (2006) using a sample of American domestic tourists in clustering the tourists using destination image attributes, obtained 3 distinct clusters of tourists who used travel information from travel professionals differently. However, their study utilized destination image attributes rather than the commonly accepted cognitive and affective destination image dimensions. Moreover, the only source of information used to explore the cluster differences was professional travel organization. Therefore, to complement the previous studies, the 
current study aimed to, among other things, explore different tourist segments basing on their destination image and the travel information sources used.

\section{Methods}

\subsection{Research instruments}

The study used a structured self-administered questionnaire with two main sections capturing destination image and demographic variables. Destination image questions were framed in 5 point Likert scale with 1 indicating strong agreement with the statements while 5 stood for strong agreement with the statement. A neutral point of 3 served in demarcating agreement and disagreement with the statements. The demographic questions were framed either in categories or requiring the respondents to fill in. In order to maintain the reflective nature of destination image items within tourism, the two main destination image dimensions, cognitive and affective were captured with items derived from previous studies (Beerli \& Martin, 2004a; Baloglu \& McCleary, 1999; Lin et al., 2007).

\subsection{Data collection}

Trained research assistants were used to collect data from two major international airports in Tanzania (Julius Nyerere and Kilimanjaro airports). Permission from the airports authorities were obtained, which allowed the research assistants to have access to the departure lounge. The research assistants were instructed to approach the tourists while waiting for their flights in the departure lounge, and explain the research objectives to the potential respondents. Using departing tourists rather than prospective tourists, arriving tourists or tourists consuming the destination offers more realistic assessment of the actual destination image (Ritchie et al., 2017). Upon agreeing to participate in the study, a tourist was given a copy of the questionnaire by the research assistants. The questionnaire was picked later after the tourists had filled it in and before their departure. The questionnaires were administered for four weeks in July 2016. A total of 625 copies of the questionnaire were filled in and returned out of 650 copies that were distributed. The high response rate $(96.1 \%)$ is attributed to the personal means of data collection. After distributing the questionnaires, the research assistants made a close follow up to ensure that they get filled in and returned by the tourists before their departure. With the 8 destination image items that were used in factor analysis, with each assuming to be an independent dimension, the sample size in this study exceeds the recommended size of a minimum sample, which is 70 times the number of variables used in the segmentation process (Dolnicar et al., 2013).

\subsection{Data analysis}

Since segmentation studies are more exploratory in nature and context based (Dolnicar, 2014), it is important to undertake segmentation using posterior or data driven approach (Dolnicar et al., 2013). The data were subjected to both descriptive and inferential tests using SPSS 21.0 for Windows. The demographic variables were analysed using descriptive tests. The destination image items were subjected to exploratory factor analysis using principal component analysis with varimax rotation before the performance of cluster analysis, implying the use of factor-cluster analysis approach in segmenting the tourism market (Dryglas $\&$ Salamaga, 2017; Prayag, 2010). Though the factor-cluster analysis approach in segmenting markets has been criticized for being less powerful (Dolnicar \& Grun, 2008), it was used in the study due to its parsimonious nature in reducing the items that can be considered to differentiate the segments. After the reduction of the image items using factor analysis, the items under each factor were tested for reliability (Cronbach alpha). A two step clustering procedure with hierarchical followed by non-hierarchical cluster analysis (K-means) were used to obtain few different clusters. A discriminant analysis was performed to validate the results obtained from cluster analysis (Dryglas \& Salamaga, 2017). The clusters were then compared using t-test, ANOVA, and Chi-square to appraise the statistical significant difference among the clusters.

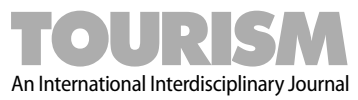




\section{Results}

\subsection{Sample profile}

The descriptive analysis yielded the socio-demographic and travel characteristics information as shown in Table 1. The sample was almost equally distributed with respect to gender, with $50.4 \%$ being females. A greater number of the respondents $(83.9 \%$ ) had an education level of university degree and above. On appraising the country of residence of the respondents, more than a half $(58.7 \%)$ originated from Europe. The mean age of the respondents was 35 years.

Table 1

Demographic profile

\begin{tabular}{l|c|c}
\hline Variable & $\begin{array}{c}\text { Frequency } \\
\text { (mean) }\end{array}$ & $\begin{array}{c}\% \\
\text { (Stdev.) }\end{array}$ \\
\hline Gender & 309 & 49.6 \\
Male & 314 & 50.4 \\
$\quad$ Female & & \\
\hline Level of education & 17 & 2.8 \\
$\quad$ Less than high school & 80 & 13.3 \\
Less than college & 382 & 63.3 \\
University degree & 124 & 20.6 \\
$\quad$ Postgraduate degree & & \\
\hline Country of residence & 367 & 58.7 \\
Europe & 92 & 14.7 \\
America & 29 & 4.6 \\
Asia & 60 & 9.6 \\
Australia/New Zealand & 56 & 9.0 \\
Africa & 15 & 2.4 \\
$\quad$ Middle East & $(35.62)$ & $(12.60)$ \\
\hline Age in years &
\end{tabular}

\subsection{Factor and reliability analyses}

The 8 destination image items were subjected to exploratory factor analysis using principal component analysis and varimax rotation with three dimensions resulting from the analysis (Table 2). The KMO measure of sampling adequacy was above .60 which is acceptable (Hair et al., 2010), and the Bartlett's test of sphericity was significant. The three resulting dimensions were labeled as nature cognitive destination image, cultural cognitive destination, and affective destination image that accounted for $70.464 \%$ of the variance in the data. The reliability of the items in measuring the respective dimensions were calculated with the Cronbach alpha for the three destination images being around the recommended level of .70 (Hair et al., 2010), indicating the items to reliably measure destination image.

Table 2

Validity and reliability tests for study variables

\begin{tabular}{|c|c|c|c|c|c|}
\hline \multirow[b]{2}{*}{ Scale items } & \multirow[b]{2}{*}{ Mean } & \multirow{2}{*}{$\begin{array}{l}\text { Std. } \\
\text { dev. }\end{array}$} & \multicolumn{3}{|c|}{ Factor loading } \\
\hline & & & $\begin{array}{c}\text { Cognitive } \\
\text { nature }\end{array}$ & $\begin{array}{l}\text { Cognitive } \\
\text { culture }\end{array}$ & Affective \\
\hline Tanzania is rich in flora and fauna & 4.49 & .811 & .878 & & \\
\hline Tanzania has a mesmerizing landscape & 4.44 & .808 & .841 & & \\
\hline Tanzania has attractive beaches & 4.23 & .925 & .514 & & \\
\hline Tanzania has many places of historical and cultural interests & 3.80 & 1.005 & & .892 & \\
\hline Tanzania has lots of interesting cultural activities & 3.70 & 1.080 & & .874 & \\
\hline Tanzania is a boring destination & 1.51 & 1.025 & & & .856 \\
\hline Tanzania is an unpleasant place for tourists & 1.65 & 1.053 & & & .819 \\
\hline
\end{tabular}




\begin{tabular}{|c|c|c|c|c|c|}
\hline \multirow[b]{2}{*}{ Scale items } & \multirow[b]{2}{*}{ Mean } & \multirow[b]{2}{*}{$\begin{array}{l}\text { Std. } \\
\text { dev. }\end{array}$} & \multicolumn{3}{|c|}{ Factor loading } \\
\hline & & & $\begin{array}{c}\text { Cognitive } \\
\text { nature }\end{array}$ & $\begin{array}{c}\text { Cognitive } \\
\text { culture }\end{array}$ & Affective \\
\hline Tanzania is a gloomy destination & 1.96 & 1.325 & & & .767 \\
\hline$\%$ variance explained & & & 23.531 & 21.472 & 25.564 \\
\hline Cronbach alpha & & & .685 & .790 & .750 \\
\hline
\end{tabular}

KMO .688 Bartlett's Test of Sphericity (Chi-square1506.537, p.000)

\subsection{Clusters of tourists by destination image}

Following the factor and reliability analysis, hierarchical cluster analysis was performed as a means of exploring the number of clusters from the data with the results and the dendrogram indicating the presence of 3 clusters. Thereafter, the hierarchical cluster analysis using K-means was performed to confirm the 3 cluster solution. Follow up ANOVA and Chi-square tests indicated that the three cluster solution obtained indicated the 3 clusters to be statistical significant with respect to destination image, sources of travel information, travel motivations, demographic and travel behavior (Table 2). The three clusters can be arranged on a continuum with cognitive and affective image being the anchors. The first cluster $(34.2 \%)$ is labeled as ambivalent as it is composed travelers with neither strong cognitive nor strong affective destination image. The second cluster which was the smallest $(9.5 \%)$ with a higher affective destination image and average cognitive image is named affective-cognitive travelers. The third cluster (56.2\%) constitutes travelers who are high in cognition and thus labeled as cognitive travelers. The cognitive cluster (cluster 3 ) is likely to consist of females who are motivated to travel for nature and culture of the destination and who travel as fully package travelers. They also prefer to use information centres as a source of travel information. The cluster with high affective image (cluster 2) is likely to constitute older males who travel as fully independent travelers. Other clusters are more likely to start planning and searching for travel information much earlier.

Table 3

Cluster analysis results

\begin{tabular}{|c|c|c|c|c|c|c|c|}
\hline Variable & $\begin{array}{l}\text { Overall } \\
\text { mean }\end{array}$ & $\begin{array}{l}\text { Std. } \\
\text { dev. }\end{array}$ & $\begin{array}{c}\text { Affective- } \\
\text { cognitive } \\
(34.2 \%)\end{array}$ & $\begin{array}{c}\text { Ambiva- } \\
\text { lents } \\
(9.5 \%)\end{array}$ & $\begin{array}{c}\text { Cognitive } \\
(56.2 \%)\end{array}$ & $\begin{array}{l}\text { F value } \\
(t \text { value } \\
\left.\text { or } x^{2}\right)\end{array}$ & $P$ value \\
\hline Cognitive nature image & 4.3845 & .66577 & $4.5407^{b}$ & $3.1803^{\mathrm{a}}$ & $4.5072^{b}$ & 171.026 & .000 \\
\hline Cognitive culture image & 3.7488 & .94823 & $3.9331^{\mathrm{a}}$ & $2.3197^{b}$ & $3.8947^{\mathrm{a}}$ & 101.647 & .000 \\
\hline Affective image & 1.7077 & .93308 & $2.7848^{\mathrm{a}}$ & $2.7541^{\mathrm{a}}$ & $1.2487^{\mathrm{b}}$ & 401.689 & .000 \\
\hline Age & & & $36.78^{\mathrm{a}}$ & $39.00^{\mathrm{ab}}$ & $34.82^{\mathrm{b}}$ & 3.60 & .028 \\
\hline Gender (Males) & & & $55.90 \%$ & $55.70 \%$ & $46.90 \%$ & 4.211 & .122 \\
\hline Full package & & & 43.90 & 23.70 & 34.30 & 13.976 & .007 \\
\hline Partial package & & & 24.40 & 45.80 & 27.10 & & \\
\hline Fully independent traveler & & & 31.70 & 30.50 & 38.50 & & \\
\hline $\begin{array}{l}\text { Planning horizon } \\
\text { Within } 1 \text { month } \\
1 \text { to } 3 \text { months } \\
\text { More than } 3 \text { months }\end{array}$ & & & $\begin{array}{r}1.60 \\
36.20 \\
62.20\end{array}$ & $\begin{array}{l}14.80 \\
44.30 \\
41.00\end{array}$ & $\begin{array}{r}4.10 \\
46.60 \\
48.30\end{array}$ & 24.089 & .000 \\
\hline
\end{tabular}

Note: The \% reported are within cluster percentages.

\subsection{Discriminant analysis}

A follow up discriminant analysis was performed to validate the results obtained from cluster analysis, as shown in Table 4. The average scores for the three destination image factors obtained from the factor analysis were used as independent variables while the cluster membership was used as the dependent variable. The canonical correlation coefficient was moderately high (above .50) with the first and second discriminant function having values of .771 and .603 respectively. The first function isolates $72 \%$ of intergroup variance compared to 
the second function that isolates the intergroup variance to the tune of $28 \%$. The function coefficients show Function 1 to be primarily defined by nature based cognitive destination image, cultural based destination image, and affective image. In general, the model successfully classified the respondents into their respective groups by $93.4 \%$ with the highest classification percentage being for the cognitive cluster $(95.2 \%)$ followed by affective-cognitive group $(91.8 \%)$ and finally the ambivalent group $(88.2 \%)$.

Table 4

Discriminant analysis of tourists

\begin{tabular}{|c|c|c|c|c|c|c|c|}
\hline Function & $\begin{array}{l}\text { Eigen- } \\
\text { value }\end{array}$ & $\begin{array}{l}\text { Var. ex- } \\
\text { plained } \\
(\%)\end{array}$ & $\begin{array}{l}\text { Canoni- } \\
\text { cal cor- } \\
\text { relation }\end{array}$ & $\begin{array}{c}\text { Wilks' } \\
\text { lambda }\end{array}$ & $X^{2}$ & df & $p$ \\
\hline 1 & $1.470^{\mathrm{a}}$ & 72.0 & .771 & .258 & 841.788 & 6 & .000 \\
\hline 2 & $.570^{\mathrm{a}}$ & 28.0 & .603 & .637 & 280.258 & 2 & .000 \\
\hline \multirow[t]{2}{*}{ Discriminant loading } & & & Function & & & & \\
\hline & & & 1 & 2 & & & \\
\hline Nature cognitive image & & & $.904^{*}$ & .395 & & & \\
\hline Culture cognitive image & & & -.415 & $.721^{*}$ & & & \\
\hline Affective image & & & -.320 & $.555^{*}$ & & & \\
\hline
\end{tabular}

As a means of exploring the relationships between the three tourist clusters and the travel information sources used, a series of one way ANOVA was performed with the clusters as the grouping variables and the responses for the extent of usage of the different travel information sources as the test variables. The results, which are summarized in Table 5, show that friends and relatives, information centres, and fairs and exhibitions were the travel information sources used by the three tourist clusters. Friends and relatives as a source of information is relatively less used by the cognitive cluster compared to the other clusters. Tourist information centers are less used by the affective-cognitive clusters, unlike the other two clusters. Fairs and exhibitions as sources of travel information are more commonly used by the ambivalent group followed by the affective-cognitive cluster, while the cognitive cluster tend to use it to a lesser extent.

Table 5

Sources of travel information used by the clusters

\begin{tabular}{l|c|c|c|c|c|c|c}
\hline Information source & Mean & Stdev. & $\begin{array}{c}\text { Affective- } \\
\text { cognitive }\end{array}$ & $\begin{array}{c}\text { Ambiva- } \\
\text { lent }\end{array}$ & Cognitive & F value & P value \\
\hline The internet & 3.9385 & 1.18722 & 3.9444 & 3.7049 & 3.9698 & 1.334 & .264 \\
Friends and relatives & 2.9172 & 1.38093 & $3.0242^{\mathrm{ab}}$ & $3.2787^{\mathrm{a}}$ & $2.8353^{\mathrm{b}}$ & 3.244 & .040 \\
Books and magazines & 2.7659 & 1.36873 & 2.9213 & 2.7667 & 2.7196 & 1.063 & .346 \\
Hotels and restaurants & 1.9342 & 1.10217 & 2.1290 & 2.0000 & 1.8679 & 2.828 & .060 \\
Information centres & 2.0393 & 1.25753 & $2.2000^{\mathrm{a}}$ & $1.7049^{\mathrm{b}}$ & $2.0401^{\mathrm{a}}$ & 3.200 & .041 \\
Advertisements & 1.8382 & 1.07416 & 2.0480 & 1.7541 & 1.7887 & 3.043 & .048 \\
Fairs and exhibitions & 1.6344 & .96870 & $1.8780^{\mathrm{a}}$ & $1.7049^{\mathrm{ab}}$ & $1.5540^{\mathrm{b}}$ & 5.603 & .004 \\
Other sources & 1.9422 & 1.37929 & 2.0484 & 1.8333 & 1.9243 & .291 & .748 \\
\hline
\end{tabular}

The results of one way ANOVA tests relating the three tourist clusters and their travel motives are presented as Table 6. The results show that the ambivalent and cognitive clusters are motivated to travel by the same factors, except for experience safari, which is more relevant to the ambivalents compared to the cognitive group. The affective-cognitive cluster significantly differs from the other clusters with all the travel motives significantly scoring less than the other clusters. 
Table 6

Travel motives by tourist clusters

\begin{tabular}{l|c|c|c|c|c|c|c}
\hline Motive & Mean & Stdev. & $\begin{array}{c}\text { Affective- } \\
\text { cognitive }\end{array}$ & $\begin{array}{c}\text { Ambiva- } \\
\text { lent }\end{array}$ & $\begin{array}{c}\text { Cogni- } \\
\text { tive }\end{array}$ & F value & P value \\
\hline Visit historical and cultural sites & 3.51 & 1.236 & $3.80^{\mathrm{a}}$ & $2.72^{\mathrm{b}}$ & $3.53^{\mathrm{a}}$ & 16.687 & .000 \\
Learn about local culture & 3.96 & 1.056 & $4.09^{\mathrm{a}}$ & $3.17^{\mathrm{b}}$ & $4.04^{\mathrm{a}}$ & 20.324 & .000 \\
Be close to nature & 4.11 & 1.138 & $4.38^{\mathrm{a}}$ & $3.51^{\mathrm{b}}$ & $4.11^{\mathrm{a}}$ & 12.553 & .000 \\
Visit wildlife areas & 4.09 & 1.302 & $4.43^{\mathrm{a}}$ & $3.34^{\mathrm{b}}$ & $4.09^{\mathrm{a}}$ & 14.704 & .000 \\
Experience safari & 3.89 & 1.465 & $4.35^{\mathrm{a}}$ & $3.37^{\mathrm{b}}$ & $3.82^{\mathrm{c}}$ & 10.791 & .000 \\
$\begin{array}{l}\text { Learn/understand different } \\
\text { cultures and ways of life }\end{array}$ & 4.00 & 1.097 & $4.17^{\mathrm{a}}$ & $3.36^{\mathrm{b}}$ & $4.04^{\mathrm{a}}$ & 12.121 & .000 \\
\hline
\end{tabular}

\section{Discussions and implications}

Segmenting tourists based on their image of a particular destination offers insights to marketers on segmenting and marketing their destinations. This study presents a segmentation analysis of tourists visiting Tanzania basing on the cognitive and affective destination images utilizing the factor-clustering method. The results of factor analysis divided the cognitive destination image into nature and cultural images and retained affective destination image as a single factor. The three dimensions of destination image explained about $70 \%$ of the variance in destination image for the inbound tourists to Tanzania. The results from the cluster analysis affirm the utility of the two destination image dimensions in segmenting travel markets, with the resulting segments indicating statistical significance among the clusters on mode of travel, travel motives, sources of travel information, and planning horizon. The cognitive cluster has the majority of tourists who have a more positive cognitive image of the destination.

The results of the present study offer several theoretical implications. Foremost, the results from factors analysis support the conceptualization and operationalization of destination image into cognitive and affective parts (Baloglu \& McCleary, 1999; Beerli \& Martin, 2004a). The two sub-dimensions of the cognitive image support previous findings, indicating the cognitive destination image to be composed of several dimensions unlike the affective which is a single component (Martin-Santana et al., 2017; Stylidis et al., 2017). As the cognitive-nature, cognitive-cultural, and affective destination image components contributed about $70 \%$ of variations in the destination image, then it can be concluded that these components contribute much on the variations of destination image compared to the other cognitive components such as infrastructure, atmosphere, and supporting services (Beerli \& Martin, 2004a; Martin \& Bosque, 2008; Stylidis et al., 2017). Thus, the cognitive-nature and cognitive-cultural aspects are the main sub-dimensions under cognitive destination image reflecting nature and cultural as the main tourist attraction (Weaver \& Lawton, 2006). The cluster analysis results provide support on the use of destination image as a valid variable in segmenting the tourism market (Leisen, 2001; Obenour et al., 2006) particularly using both the cognitive and affective destination image dimensions. The inclusion of the affective dimension in segmenting the tourists is one of the major contributions of this study, which complements the previous studies that utilized only the cognitive dimension (e.g. Dryglas \& Salamanga, 2017; Leisen, 2001; Prayag, 2010). The affective image is considered as the major component of destination image (Beerli \& Martin, 2004a, 2004b). The demographic variable gender did not show any differences between the three clusters, and age showed a marginal difference compared to previous studies (Dryglas \& Salamanga, 2017; Leisen, 2001; Prayag, 2010). Such divergence might be attributed to the contextual factors like destination with different images that are not uniformly perceived by the different demographic groups. With respect to the use of different travel information sources by different segments, the results support those obtained by Obenour et al. (2006) and go an extra mile to include friends and relatives, information centres, and fair and exhibitions that significantly differentiate the three segments. As the three resulting tourist clusters basing on destination image showed a statistical significant variation, 
then the contention that destination image and travel motives are related is supported (Martin \& Rodriguez del Bosque, 2008). Furthermore, since some previous studies have used destination image to reflect travel motives (Prayag, 2010) particularly cognitive image that reflects pull motivation factors, then theoretically the two can be assumed to be synonymous.

Practically, the results provide insights to destination managers on the strategic use of destination image. The cognitive segment being the largest implies that managers can concentrate on providing information that is more factual, and attribute base to the potential tourists and still be successful in marketing their destinations like Tanzania, a long haul destination to most of the respondents in the current study. Deducing from the cognitive-affective group having high cognitive and affective destination image, managers can capitalize on their possible sources of information in targeting them. Since this group tends to use more of information centres, advertisements, and trade fairs, managers should ensure the communications via these channels have both cognitive and affective stimulating information. Moreover, as the cognitive-affective group has diverse travel motivations, marketers should ensure that their communication materials contain the different motives in targeting such a segment. Specifically, destination marketers upon appraising which segments among the three that were identified in the current study can opt to target one or more segments using different marketing strategies. For instance, using travel behavior, a marketer can try to provide travel information well in advance for the affective-cognitive group who have high planning horizon and who are likely to travel as fully package travelers. For the ambivalent group, destinations marketers can leverage by providing information through both travel intermediaries and direct marketing as members of this group are likely to travel as partial package travelers. The travel information to this group should be communicated more than a month before travel date as this group tends to plan their travel extensively for more than one month before they travel. The information to the cognitive group can be distributed to travel intermediaries like tour operators and travel agents as well as through direct marketing as the cluster does not show any preference with respect to travel mode. Generally, the results from this study do not offer strong evidence to indicate that the different clusters basing on destination image differ on the demographic variables, particularly gender. At least for age, there is a marginal difference, with the ambivalent and affective-cognitive groups being relatively younger compared to the cognitive group. Thus marketers, at least within the Tanzanian context, should be cautious when using demographic variables to segment the markets.

Despite the current study offering several implications, the interpretations of the results should consider the inherent caveat of the study. First, the study was undertaken in a less developed region, the sub-Saharan African country (Tanzania) where the majority of tourists are from the developed countries, implying a long haul travel. Thus, the findings might not be applicable to a short-haul destination. With the cognitive destination image being dominant, with many tourists evaluating it as more favourable compared to the affective component, studies should be dedicated to test a plausible proposition that 'long-haul tourists have a higher cognitive destination image than short-haul tourists who have a higher affective image'. As the study captured the post-visit destination image only (Jani \& Nguni, 2016) which might be different from the previsit destination image (which determines if a tourist visits a destination), future studies can add to the body of knowledge by segmenting the tourist using their pre- as well as their post-destination images to appraise the stability of the segments.

\section{Acknowledgement:}

This work was supported by the Seed Program for Korean Studies through the Ministry of Education of the Republic of Korea and the Korean Studies Promotion Service of the Academy of Korean Studies (AKS-2018-INC-2230005).

\section{References}

Avraham, E., \& Ketter, E. (2016). Tourism marketing for developing countries: Battling stereotypes and crises in Asia, Africa and Middle East. Palgrave Macmillan. 
Baloglu, S., \& McCleary, K.W. (1999). A model of destination image formation. Annals of Tourism Research, 26(4), 868-896.

Beerli, A., \& Martin, J.D. (2004a). Tourists' characteristics and the perceived image of tourist destinations: A quantitative analysis-a case study of Lanzarote, Spain. Tourism Management, 25, 623-236.

Beerli, A., \& Martín, J.D. (2004b). Factors influencing destination image. Annals of Tourism Research, 31(3), $657-681$.

Boo, S., \& Busser, J.A. (2005). The hierarchical influence of visitor characteristics on tourism destination images. Journal of Travel and Tourism Marketing, 19(4), 55-67.

Chiu, W., Zeng, S., \& Cheng, P.S.T. (2016). The influence of destination image and tourist satisfaction on tourist loyalty: A case study of Chinese tourists in Korea. International Journal of Culture, Tourism and Hospitality Research, 10(2), 223-234.

Crompton, J.L. (1979). Motivations for pleasure vacation. Annals of Tourism Research, 6(4), 408-424.

Dolinicar, S., Grun, B., Leish, F., \& Schmidt, K. (2013). Required sample sizes for data-driven market segmentation analyses in tourism. Journal of Travel Research, 53(3), 296-306.

Dolnicar, S. (2014). Market segmentation approaches in tourism. In S. McCabe (Ed.), The Routledge handbook of tourism marketing (pp. 197-208). Routledge.

Dolnicar, S., \& Grun, B. (2008). Challenging 'factor cluster segmentation'. Journal of Travel Research, 47(1), 63-71.

Dryglas, D., \& Salamaga, M. (2017). Applying destination attribute segmentation to health tourists: A case study of Polish spa resorts. Journal of Travel and Tourism Marketing, 34(4), 503-514.

Fernandez-Hernandez, C., Leon, C.J., Arana, J.E., \& Diaz-Perez, F. (2016). Market segmentation, activities and environmental behavior in rural tourism. Tourism Economics, 22(5), 1033-1054.

Gartner, W.C. (1993). Image formation process. Journal of Travel and Tourism Marketing, 2(2/3), 191-215.

Hair, J.F., Black, W.C., Babin, B.J., \& Anderson, R.E. (2010). Multivariate data analysis: A global perspective (7th ed.). Pearson Prentice Hall.

Hsu, C.H.C., \& Kang, S.K. (2007). CHAID-based segmentation: International visitors' trip characteristics and perceptions. Journal of Travel Research, 46, 207-216.

Jani, D., \& Nguni, W. (2016). Pre-trip vs post-trip destination image variations: A case of inbound tourists to Tanzania. Tourism: An International Interdisciplinary Journal, 64(1), 27-40.

Kim, S.S., Crompton, J.L., \& Botha, C. (2000). Responding to competition: A strategy for Sun/Lost City, South Africa. Tourism Management, 21, 33-41.

Kotler, P., \& Armstrong, G. (2014). Principles of marketing (15th ed.). Pearson Education Ltd.

Leisen, B. (2001). Image segmentation: The case of tourism destination. Journal of Service Marketing, 15(1), 49-66.

Lin, C.H., Morais, D.B., Kerstetter, D.L., \& Hou, J.S. (2007). Examining the role of cognitive and affective image in predicting choice across natural, developed, and theme-park destinations. Journal of Travel Research, 46, 183-194.

Liu, Y.D. (2014). Image-based segmentation of cultural tourism market: The perceptions of Taiwan's inbound visitors. Asia Pacific Journal of Tourism Research, 19(8), 971-987.

Martin, H.S., \& Rodrigues del Bosque, I.A. (2008). Exploring the cognitive-affective nature of destination image and the role of psychological factors in its formation. Tourism Management, 29, 263-277.

Martin-Santana, J.D., Beerli-Palacio, A., \& Nazzareno, P.A. (2017). Antecedents and consequences of destination image gap. Annals of Tourism Research, 62, 13-25.

Matiza, T., \& Oni, O.A. (2014). Managing the tourist destination image: The case of Africa. Tourism: An International Interdisciplinary Journal, 62(4), 397-406.

Obenour, W., Groves, D., \& Lengfelder, J. (2006). Image segmentation and implications for the development of a nature based destination. Journal of Hospitality and Leisure Marketing, 14, 23-47.

Prayag, G., \& Ryan, C. (2012). Antecedents of tourists' loyalty to Mauritius: The role and influence of destination image, place attachment, personal involvement, and satisfaction. Journal of Travel Research, 51(3), 342-356.

Prayag, G., Disegna, M., Cohen, S.A., \& Yan, H. (2015). Segmenting markets by bagged clustering: Young Chinese travelers to Western Europe. Journal of Travel Research, 54(2), 234-250.

Prayang, G. (2010). Images as pull factors of a tourist destination: A factor-cluster segmentation analysis. Tourism Analysis, 15(2), 213-226.

Ritchie, B.W., Chien, M., \& Sharifpour, M. (2017). Segmentation by travel related risks: An integrated approach. Journal of Travel and Tourism Marketing, 34(2), 274-289. 
Stylidis, D., Shani, A., \& Belhassen, Y. (2017). Testing an integrated destination image model across residents and tourists. Tourism Management, 58, 184-195.

Tang, Y. (2014). Travel motivation, destination image and visitor satisfaction of international tourists after the 2008 Wenchuan earthquake: A structural modelling approach. Asia Pacific Journal of Tourism Research, 19(11), $1260-1277$.

Tasci, A.D.A, Gartner, W.C., \& Cavusgil, S.T. (2007). Conceptualization and operationalization of destination image. Journal of Hospitality \& Tourism Research, 31(2), 194-223.

Tasci, A.D.A., \& Gartner, W.C. (2007). Destination image and its functional relationships. Journal of Travel Research, 45(4), 413-425.

Tativiyama, P, \& Qu, H. (2013). Destination image and behavioral intention of travelers to Thailand: The moderating effect of perceived risk. Journal of Travel and Tourism Marketing, 30(3), 169-185.

Tkaczynski, A., \& Rundle-Thiele, S. (2011). Segmenting destinations: In the eyes of the stakeholders. International Journal of Culture, Tourism and Hospitality Research, 5(3), 255-268.

Wang, C., \& Hsu, M.K. (2010). The relationships of destination image, satisfaction and behavioral intentions: An integrated model. Journal of Travel and Tourism Marketing, 27(8), 829-843.

Weaver, D., \& Lawton, L. (2006). Tourism management (3rd ed.). John Wiley and Sons, Ltd.

Zhang, H., Fu, X., Cai, L.A., \& Lu, L. (2014). Destination image and tourist loyalty: A meta-analysis. Tourism Management, 40, 213-223.

Submitted: January 17,2020

Revised: June 24, 2020

Accepted: August 05, 2020

Refereed Anonymously 